\title{
Teknologi Knowledge Management: Peran TI Terhadap Pengelolaan Knowledge
}

\author{
Oleh: Mahendra Adhi Nugroho \\ Akuntansi FISE UNY
}

\begin{abstract}
Abstrak
Artikel ini akan membahas peran dan pengaruh TI secara komprehensif dalam pengelolaan knowledge dalam organisasi. Pembahasan dimulai dari peran dan perkembangan TI dalam penkomunikasian knowledge, peran TI dalam mentranfromasikan knowledge, peran TI dalam penyebaran knowledge melalui jaringan, perkembagan teknologi knowledge manajemen, dan diakhiri dengan aplikasi TI berbasis knowledge dalam organisasi. Dari semua peran tersebut dapat di simpulkan bahwa TI dapat meningkatkan efektifitas pengelolaan knowledge yang berdampak pada peningkatan sinergi organisasi.
\end{abstract}

Knowledge

Kata kunci: Teknologi Informasi, Pengelolaan Knowledge, TI berbasis

\section{Pendahuluan}

Perkembangan teknologi informasi (TI) dewasa ini telah merambah di seluruh sendi kehidupan. Pengadopsian teknologi informasi dalam organisasi telah berlangsung sejak teknologi itu sendiri ada. Tidak dapat dipungkiri bahwa perkembangan teknologi dimotori oleh kebutuhan suatu organisasi untuk meningkatkan kinerja organisasi. Peningkatan kinerja organisasi tidak hanya diukur dari seberapa besar dan cepat suatu organisasi mengadopsi TI untuk mendukung opreasinya tetapi juga kemampuan organisasi untuk memperbaiki kesalahan atau kegagalan yang pernah dilakukannya.

Pengetahuan (knowledge) merupakan hal yang sangat penting dalam organisasi. Knowledge merupakan konsep yang komplek (Nonaka, 1994 dalam Sambamurthy dan Subramani 2005). Knowledge dalam organisasi mengacu pada memori organisasi terhadap seluruh aktivitas yang telah dilakukannya. Memori organisasi tersebut berperan sebagai basis data yang dapat menjadi otak suatu organisasi. Tidak hanya memori mengenai aktivitas operasional organisasi tetapi juga memori mengenai budaya dan gaya organisasi. Setiap organisasi mempunyai teknik dan metode yang berbeda-beda dalam menyimpan dan mengelola knowledge organisasi mereka. Dalam pengelolaan knowledge TI mampu mendukung hampir setiap sendi pengelolan knowledge.

Peran TI dalam pengelolaan knowledge sangat komprehensif dari hanya sekedar sebagai alat komunikasi sampai dengan pengelolalaan knowledge suatu organisasi yang sangat komplek. Perkembangan TI untuk alat komunikasi dari 
sekedar untuk berbicara dewasa ini berkembang menjadi sebgai forum diskusi. Dalam organisasi efek perkembagan tersebut mampu mengubah strategi bisnis dan pembentukan budaya organisasi yang mendukung kinerja perusahan. Dalam artikel ini akan membahas peran dalam pengelolanan knowledge secara komprehensif yang dimulai dengan peran TI dalam meperlancar kanal infomasi sampai dengan pembentukan Community of Practice $(\mathrm{CoP})$

\section{TI Adalah Segalanya: Dari Columbus Sampai WIKI}

Beberapa abad yang lalu suatu pemikiran mengenai kondisi bumi yang bulat yang di lontarkan oleh Copernicus menantang para penjelajah lautan untuk memutari bumi. Suatu tindakan yang menentang konsep bumi datar yang ada sebelumnya. Dari banyak penjelajah, Columbus salah satu penjelajah, pertama kali mengangkat sauh pada tahun 1492 untuk misi 3G (God, Gold, Glory) yang dipersembahkan untuk negaranya. Untuk pertama kalinya, ekpedisi Columbus menemukan benua Amerika. Pada awal pendudukan benua, Columbus menemukan dan menduduki pulau kecil di dekat dataran utama benua Amerika. Dengan semangat misi 3G Columbus mencoba untuk membangun daerah tersebut. Columbus mencoba untuk memasukan knowledge baru yang berupa agama dan pemikiran cara hidup yang baru yang akhirnya menemui kegagalan.

Mengapa Columbus gagal? Knowledge merupakan konsep yang komplek dan beberapa faktor yang mendeterminasikan knowledge creation, management, valuation, dan sharing (Nonaka, 1994 dalam Sambamurthy dan Subramani 2005). Knowledge bukan merupakan aset fisik, sehingga konsep yang digunakan harus berbeda. Permasalan yang dihadapi oleh Columbus terhadap knowledge yang menjadi lebih sulit karena tidak adanya teknologi yang memadai yaitu (Sambamurthy dan Subramani 2005):

1. Permasalahan koordinasi knowledge

2. Permasalahan transfer knowledge

3. Permasalahan sharing knowledge

Bagaimana meminimalisasi permasalahan knowledge? Sejarah perjalanan manusia bergulir ke abad penemuan. Pada masa tersebut dorongan manusia untuk berkomunikasi mendorong penemuan alat komunikasi dari telegran sampai telephone. Kedua teknologi komunikasi memungkinkan untuk berbagi knowledge jarak jauh dengan cara dan kapasitas terbatas. Pada akhir abad 20 perkembangan TI semakin komplek dan fleksibel dan terus berkembang sampai awal abad 21 dan terus berlanjut. Perkembangan teknologi memungkinkan untuk berkomunikasi dan berbagi knowledge semakin fleksibel. Komunikasi mengarah pada aplikasi berbasis komputer dan mengarah ke web. Tabel 1 diambil dari Wagner (2004) menunjukan peran teknologi yang ada terhadap knowledge. 
Table 1:

Konversi Teknologi

\begin{tabular}{|c|c|c|c|}
\hline Technology & Communication & $\begin{array}{l}\text { Knowledge } \\
\text { Repository }\end{array}$ & $\begin{array}{l}\text { Knowledge } \\
\text { Catalog }\end{array}$ \\
\hline E-mail & $\begin{array}{l}\text { 1-to-1, } 1 \text {-to-many, } \\
\text { person-to-person }\end{array}$ & $\begin{array}{l}\text { Local e-mail } \\
\text { archives } \\
\text { possible }\end{array}$ & $\begin{array}{l}\text { Local index } \\
\text { possible }\end{array}$ \\
\hline $\begin{array}{l}\text { Static and } D B \\
\text { backed web } \\
\text { pages }\end{array}$ & $\begin{array}{l}\text { 1-to-many, approaching } \\
\text { many-to- many, "dialog } \\
\text { between web pages } \\
\text { through hyperlinks }\end{array}$ & Local archives & $\begin{array}{l}\text { Local index } \\
\text { possible. web } \\
\text { rings create } \\
\text { larger catalog }\end{array}$ \\
\hline $\begin{array}{l}\text { Discussion } \\
\text { forum }\end{array}$ & $\begin{array}{l}\text { Many-to-many in web } \\
\text { based forums, repeated } \\
\text { 1-to-many in list } \\
\text { servers }\end{array}$ & $\begin{array}{l}\text { Central repository } \\
\text { if web based, local } \\
\text { if list server }\end{array}$ & $\begin{array}{l}\text { Central index if } \\
\text { web based }\end{array}$ \\
\hline Internet chat & 1 -to- $1 ;$ many-to-many & $\begin{array}{l}\text { Frequently none, } \\
\text { transient } \\
\text { communication }\end{array}$ & None \\
\hline $\begin{array}{l}\text { Video/ audio } \\
\text { streaming }\end{array}$ & 1-to-many & $\begin{array}{l}\text { Central host or } \\
\text { decentralized } \\
\text { streamers }\end{array}$ & $\begin{array}{l}\text { None, streams } \\
\text { not indexed }\end{array}$ \\
\hline $\begin{array}{l}\text { Video; audio } \\
\text { conference }\end{array}$ & I-to-1, 1-to-many & $\begin{array}{l}\text { Local repository if } \\
\text { content is recorded }\end{array}$ & $\begin{array}{l}\text { None, content } \\
\text { typically not } \\
\text { indexed }\end{array}$ \\
\hline$G D S S$ & Many-to-many & $\begin{array}{l}\text { Available, but } \\
\text { GDSS } \\
\text { sessions often } \\
\text { treated as } \\
\text { one-off. }\end{array}$ & $\begin{array}{l}\text { Typically none. } \\
\text { but } \\
\text { Possible }\end{array}$ \\
\hline Web Log & $\begin{array}{l}\text { 1-to-many, can } \\
\text { approach many- } \\
\text { to-many (similar to web } \\
\text { pages) }\end{array}$ & $\begin{array}{l}\text { Local repository } \\
\text { within each } \\
\text { weblog. } \\
\text { Metablogs" now } \\
\text { emerging }\end{array}$ & $\begin{array}{l}\text { Yes, local } \\
\text { index, metablog } \\
\text { may provide } \\
\text { larger catalog }\end{array}$ \\
\hline Wiki & Many-to-many & $\begin{array}{l}\text { Yes, current } \\
\text { knowledge and } \\
\text { history ("temporal } \\
\text { database") }\end{array}$ & Yes \\
\hline
\end{tabular}

Sumber: Wagner (2004)

Trend yang paling baru sampai tulisan ini ditulis adalah trend komunikasi dan sharing knowledge berbasis pada web yang terhubung dengan internet. Salah satu bentuknya adalah Wiki. Wiki merupakan satu set halaman web yang saling terhubung (linked) yang tercipta melalui pengembangan secara incremental oleh grup dari pengguna yang berkolaborasi dan software 
digunakan untuk mengelola web site (Wagner 2004). Konsep wiki merupakan konsep knowledge sharing yang berada dalam ruang virtual dalam internet. Contoh dari wiki adalah situs wikipedia (www.wikipedia.org)

Bagaimana teknologi memfasilitasi knowledge? Secara sederhana knowledge dapat difasililitasi oleh fungsi teknologi itu sendiri. Riley (2003) memberikan gambaran yagn di sajikan pada table 2 .

Table 2:

Fungsi Teknologi Dalam Memfasilitasi Knowledge

\begin{tabular}{|l|l|}
\hline Functionality & Technology \\
Searching & Search engines \\
Categorizing & Computer languages (XML, RDF) \\
Composing & Office suite applications \\
Summarizing & Artificial intelligence \\
Storing & Storage media \\
Distributing & Networks \\
Workflow & Groupware \\
\hline
\end{tabular}

Sumber: Riley (2003)

Setelah itu semua, apa sebenarnya peran TI terhadap knowledge? TI membuat banyak perusahaan untuk membayangkan dunia baru yang dimotori (leveraged) knowledge. E-mail dan internet memungkinkan orang untuk mengetahui pemikiran terakhir dari rekan mereka tidak peduli dimana mereka berada (McDermott, 1999). Dari situ terlihat bahwa teknologi membedakan istilah $3 \mathrm{G}$ Columbus dan $3 \mathrm{G}$ telephone seluler.

\section{TI Sebagai Alat Bantu: Kantor pos Vs Komputer}

Apa yang terjadi jika komputer dengan koneksi internet dimiliki semua orang? Atau, apa yang terjadi jika komputer masuk ke dalam kantor pos? Perkembangan teknologi informasi memungkinkan komunikasi menjadi lebih mudah. Fungsi teknologi dapat menggeser fungsi kantor pos bukan hanya pengantar surat dan barang. Jika kita perhatikan pengaruh TI terhadap PT Pos Indonesia tampak jelas dari peran dan produk jasa yang ditawarkan. Dari penghapusan jasa telegram, penggunaan wesel elektronik sampai dengan jasa perbankan meluai Shar-e yang menggandeng Bank Muamalat. Dari fenomena tersebut dapat dilihat bahwa intervensi TI pada PT Pos Indonesia mampu meningkatkan kemampuan untuk berkolaborasi dengan cabang bahkan perusahaan lain melalui transfer knowledge.

Konsep bagaimana teknologi dapat mendukung transformasi knowledge digambarkan oleh Marwick (2001) dengan mengadopsi knowledge creation Nonaka (1994). Marwick (2001) mencotohkan teknologi dapat mendukung melalui peran yang disajiakan pada tabel 3 . 
Table 3:

Dukungan Teknologi Dalam Knowledge Sharing

\begin{tabular}{|l|l|}
\hline $\begin{array}{l}\text { Tacit to Tacit } \\
\text { E-Meetings } \\
\text { Synchronous collaboration (chat) }\end{array}$ & $\begin{array}{l}\text { Tacit to Explicit } \\
\text { Answering questions } \\
\text { Annotation }\end{array}$ \\
\hline $\begin{array}{l}\text { Explicit to Tacit } \\
\text { Visualization } \\
\begin{array}{l}\text { Browsable video/audio of } \\
\text { presentations }\end{array}\end{array}$ & $\begin{array}{l}\text { Explicit to Explicit } \\
\text { Text Search } \\
\text { Document categorization }\end{array}$ \\
\hline
\end{tabular}

Sumber: Marwick (2001)

Kemudian, bagaimana teknologi dapat berperan? Dalam menghubungkan suatu fungsi dan peran diperlukan suatu agen teknologi, agen tersebut berfungsi untuk mengantarkan dan sebagai perantara antar fungsi. Agen teknologi dapat berupa software aplikasi tertentu yang dibangun untuk koordinasi, komunikasi, menyimpan knowledge secara integratif dan fungsi lain. Contoh sederhana dari agen teknologi adalah aplikasi catalog elektronik perpustakaan online atau aplikasi e-mail dan messenger. Konsep agen teknologi dapat dilihat pada Abdullah et al (2005).

\section{TI dan Knowledge: Microsoft dan Google}

Pada tahun 80-an windows muncul dengan segala keunggulannya dari sistem operasi DOS yang pada saat itu digunakan hampir seluruh produsen komputer. Secara tidak langsung, Microsoft mampu menggeser produsen komputer lain seperti IBM dan Apple. Meskipun diimbangi oleh open source dominasi Microsoft semakin kuat pada 9 Agustus 1995 saat windows mengeluarkan Netscape yang merupakan jaringan PC windows. Dengan aplikasi tersebut memungkinkan untuk membuat jaringan berbasis windows antar PC dan memungkinkan koneksi dengan internet menjadi lebih mudah. Seiring dengan perkembangan teknologi jaringan dan terkoneksi dengan internet, banyak bermunculan juga aplikasi berbasis web. Aplikasi tersebut diwujudkan dalam suatu situs web yang dapat dilihat sampai sekarang jika kita mengakses internet. Salah satu situs penyedia pencarian knowledge yang pertama di internet, khususnya untuk knowledge yang terstruktur adalah www.google.com. Situs merupakan searching engine yang terbesar sampai tulisan ini ditulis. Pada perkembangannya, banyak pengelola web mencantumkan searching engine pada web mereka yang memudahkan pengguna.

Kemudian, apa hubungan dengan organisasi? TI merupakan salah satu komponen penting dalam pengelolaan knowledge yang ada dalam organisasi. Dalam organisasi tool dan ifrastuktur teknologi sangat mempengaruhi 
pengelolaan knowledge yang ada. Duffy (2001) memberikan gambaran tool dan infrastruktur dari pengelolaan knowledge yang terdiri dari:

1. Infrastruktur data warehousing $\rightarrow$ merupakan infrastruktur (hardware dan software) untuk menyimpan, dan akses kembali knowledge.

2. Sistem manajemen businessware $\rightarrow$ memberikan dukungan akses integrasi aplikasi real time dan otomatisasi proses bisnis

3. Aplikasi kolaboratif $\rightarrow$ merupakan fungsi inti termasuk e-mail, database, penjadwalan, database, dll.

4. Software akses $\rightarrow$ aplikasi yang digunakan untuk mengakses knowledge yang ada.

Setelah mengetahui tool dan infrastruktur TI dalam manajemen knowledge, bagaimana struktur yang mendukung? Struktur teknologi merupakan rangkaian teknologi dan jaringan pendukung dalam knowledge. Secara garis besar Zeleny (2002) membedakan teknologi dalam komponen hardware, software, brainware dan ditambah jaringan pendukung teknologi. Hubungan antar struktur tersebut dapat dilihat pada gambar 1.

\section{Gambar 1:}

Hubungan Antar Struktur Teknologi

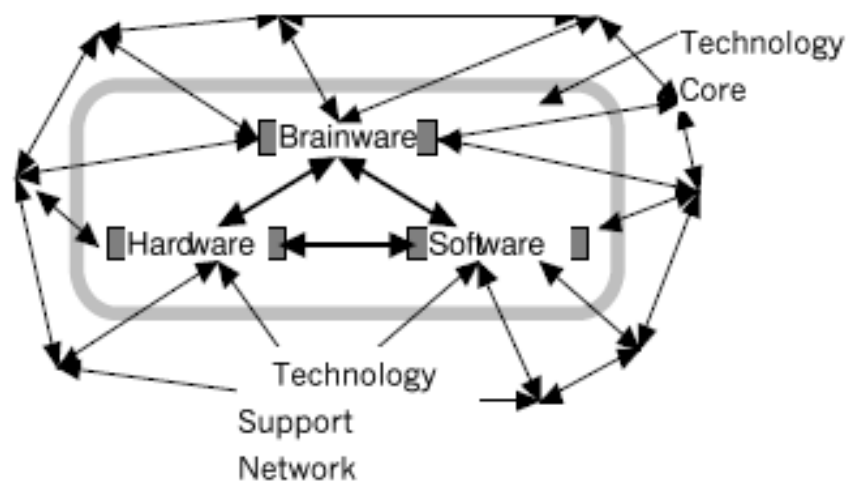

\section{Perkembangan TI: Sequel James Bond}

Sequel cerita James bond menggambarkan pandangan manusia mengenai arti dari kecangihan teknologi. Jika kita rangkai, seri James bond berdasarkan tahun pembuatan memberikan gambaran teknologi pada saat film dibuat. Kita ambil contoh teknologi yang digunakan pada mobil bond. Pada serial tahun 80an dan awal 90-an (License to Kill, The Man With Golden Gun, dll) teknologi yang dipasang pada mobil bond cenderung bersifat fungsional sederhana seperti peluncur roket, pelontar paku di jalan, dan beberapa fungsi komunikasi. Secara cukup signifikan berbeda dengan peralatan yang terpasang pada mobil bond pada film yang dibuat pada akhir tahun 90-an dan awal 2000-an (die another day, casino royal, dll). Pada masa tersebut, mobil bond tidak hanya berfungsi sebagai alat untuk melarikan diri. Di samping teknologi persenjataan, 
mobil bond dimasukan teknologi komputer yang cukup canggih, mulai dari sistem GPS sampai dengan fungsi komputer yang supercanggih yang berhubungan dengan satelit dan memungkinkan untuk berhubungan dengan markas dan pusat data dimana pun berada.

Apa hubungan James bond dengan perkembangan TI? Perkembangan TI mempengaruhi pola pikir dan pola hubungan sosial. Cerita James bond dibangun berdasarkan pencapaian kemajuan teknologi yang ada. Sistem GPS dan jaringan komputer pada mobil bond muncul setelah kemajuan teknologi jaringan komputer dan telephone seluler berkembang pesat yang dimulai pertengahan tahun 90-an. Atau dalam kehidupan nyata, telepon dengan tatap muka dimungkinkan setelah teknologi 3G ditemukan.

Kemudian, bagaimana perkembangan TI sesungguhnya? Allen (2003) memberikan urutan perkembangan PDA (Personal Diary Assistant) pada awal perkembangan dari 1988 - 1997 berdasar frame teknologi disajikan dalam tabel 4.

Tabel 4:

Perkembangan PDA 1988 -1997

\begin{tabular}{|c|c|c|c|}
\hline Proposed Frame & Problem & Performance Criteria & $\begin{array}{l}\text { Candidate Exemplary } \\
\text { Artifacts }\end{array}$ \\
\hline $\begin{array}{l}\text { Palmtop } \\
\text { computers }\end{array}$ & $\begin{array}{l}\text { Very small } \\
\text { computers }\end{array}$ & $\begin{array}{ll}- & \text { Size } \\
\text { - } & \text { Computing power } \\
\text { - } & \text { Computer } \\
& \text { applications }\end{array}$ & $\begin{array}{l}\text { Atari Portfolio 0989) } \\
\text { HP 95LX (1991) } \\
\text { Poqet PC (1989) }\end{array}$ \\
\hline $\begin{array}{l}\text { Pen based } \\
\text { computers }\end{array}$ & \begin{tabular}{|l|} 
Information \\
for mobile \\
workers and \\
technophobes
\end{tabular} & 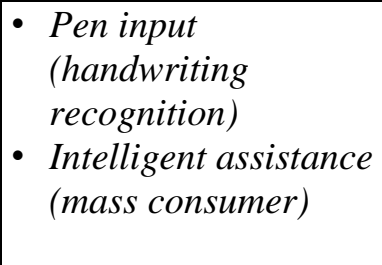 & $\begin{array}{l}\text { Apple Newton } \\
\text { MessagePad (1993) } \\
\text { Casio/Tandy Zoomer } \\
\text { (1993) } \\
\text { GRiD Convertible (1992) } \\
\text { Shan) Exise? riPad 09931 }\end{array}$ \\
\hline Communicators & \begin{tabular}{|l} 
Portable \\
wireless \\
connectivity
\end{tabular} & $\begin{array}{l}\text { - Wireless link } \\
\text { - Telephony } \\
\text { applications } \\
\text { - Pen input }\end{array}$ & \begin{tabular}{|l|} 
EO Personal \\
Communicator (1993) \\
Motorola Envoy (1995) \\
Motorola Marco (1995) \\
Sony MagicLink (1994) \\
\end{tabular} \\
\hline $\begin{array}{l}\text { Connected } \\
\text { organizers }\end{array}$ & $\begin{array}{l}\text { Small devices } \\
\text { that } \\
\text { complement } \\
\text { personal } \\
\text { computers }\end{array}$ & $\begin{array}{l}\text { - Synchronization } \\
\text { - Organizer } \\
\text { applications } \\
\text { - Computer } \\
\text { applications }\end{array}$ & $\begin{array}{l}\text { Franklin REX (1997) } \\
\text { HP 320LX (1997) } \\
\text { PaImPilot (1996) } \\
\text { Sharp SE-500 (1997) }\end{array}$ \\
\hline
\end{tabular}


Pada perkembangan selanjutnya, fungsi PDA semakin meningkat dengan fasilitas yang lebih komplek. Fungsi PDA tidak hanya organizer tetapi menuju ke arah koordinasi dan knowledge komputer dengan koneksi internet.

Kemudian, bagaimana perkembangan teknologi manajemen knowledge? Perkembangan teknologi khususnya dalam organisasi paling tidak melalui empat tingkat (Gottschalk dan Khandelwal 2004). Tingkat pertama: end user tool yang mengacu pada jaringan tiap komputer. Kedua: who knows what: informasi mengenai siap yang mengetahui sesuatu dengan membangun direktori knowledge. Ketiga: what they know mengacu pada informasi yang tersedia dengan pendekatan data mining. Keempat: how they think: sistem informasi untuk memecahkan masalah dengan pendekatan artificial intelligence. Secara grafis disajikan pada gambar 2.

Gambar 2:

Tahap Perkembangan Teknologi Manajemen Knowledge

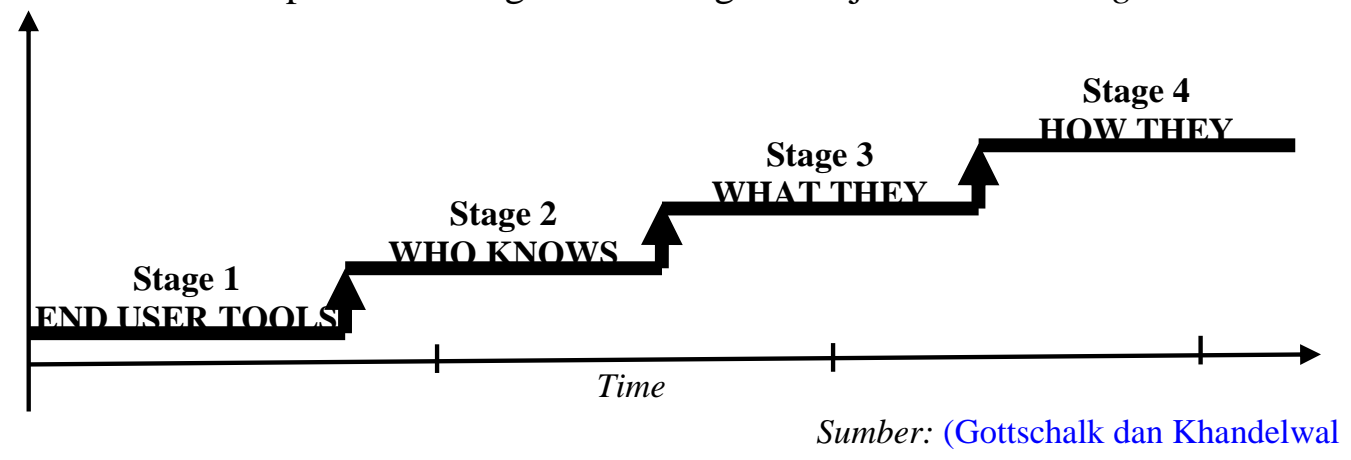

\section{Aplikasi TI berbasis knowledge: Kisah Buckman Laboratories (Tim Meek, 1999)}

Buckman Laboratories berdiri sejak 1945 dan bergerak di bidang industri obat dan kimia. Buckman mengarah ke arah perusahaan virtual. Inovasi Buckman dimulai ketika ekpansi inovasi toolset dengan menginstal sistem email pertama pada 1984. Dari permulaan tersebut kemudian mengarah ke teknologi yang mengarah pada knowledge transfer pada tahun 1989 dan pada akhirnya mengarah pada desain ulang portal dan pembangunan extranet untuk menunjang perusahaan virtualnya. Secara garis besar sejarah perjalanan inovasi teknologi berbasis knowledge Buckman dari inisiasi awal 1984 sampai 1999 disajikan pada table 5 . 
Tabel 5:

Perkembangan Komputer Dan Jaringan Tahun 1984 - 1999

\begin{tabular}{|c|c|}
\hline \multicolumn{2}{|c|}{ The Timeline } \\
\hline 1984 & Bulab's first computer access via telecommunications \\
\hline 19851 & DISOSS/PSPC e-mail system \\
\hline 19861 & Limited usage of IBM portable PC, International Access to DISOSS \\
\hline 1987 & First "laptops" in field \\
\hline 1988 & IBM Information Network (II N) replaces home-grown network access \\
\hline 1989 & Knowledge Transfer Task Force started \\
\hline 1990 & Fastpath (today this would be called a "portal") \\
\hline 1991 & R\&D electronic notebook system \\
\hline 1992 & $\begin{array}{l}\text { KTD is formed; begin conversion to Compuserve e-mail \& forums from } \\
\text { DISOSS/PSPC/PS-CICS; Compuserve Network replaces IBM Information }\end{array}$ \\
\hline 1993 & Begin conversion to Windows \\
\hline 1994 & $\begin{array}{l}\text { The name K'NetixTM is born; 4th Wave Conference; begin conversion to } \\
\text { Windows } 3 i \text { Microsaft Office WinRIM. heoin to use } I N I X \cdot R H B\end{array}$ \\
\hline 1995 & www.buckman.com goes on-line; intranet goes on-line; begin on-line learning \\
\hline 1996 & TCP/IP becomes network standard (KNA/KAM) with Netscape browser \\
\hline 1997 & First search engine on Intranet; begin ERP system implementations \\
\hline 1998 & $\begin{array}{l}\text { Conversion from Compuserve to Internet; e-mail; newsgroups, global upgrade } \\
\text { to Office } 97 \text { and Windows 95; removal of mainframe system }\end{array}$ \\
\hline 1999 & Intranet portal redesign; extranet development \\
\hline
\end{tabular}

Sumber: Tim Meek, (1999)

Setelah mengetahui perjalanan teknologi knowledge Buckman, bagaimana teknologi dapat bekerja? Dalam teknologi tersebut terdapat tool komunikasi yang memungkinkan untuk berkomunikasi. Tool tersebut memungkinkan orang berkomunikasi dengan menembus batas geografis. Fitur tool komunikasi people-to-people mempunyai fitur sebagai beberapa fitur berikut (Shand, 1998): Real Time Alerts and Messaging, Live Chat, Threaded Discussions, Electronic Whiteboard, Document Collaboration, Team Room Project Management. Fitur tersebut bekerja sebagai fasilitator untuk transfer knowledge.

Selanjutnya, bagaimana knowledge dalam organisasi ditrasnfer? Transfer knowledge dalam organisasi dapat dilakukan secara formal maupun non formal baik secara langsung maupun elektronik. Mode dan formalitas transfer knowledge digambarkan oleh Kirkland (2002) disajikan pada gambar 3. 
Gambar 3:

Mode dan Formalitas Transfer Knowledge

\begin{tabular}{|c|c|c|}
\hline \multirow{3}{*}{ 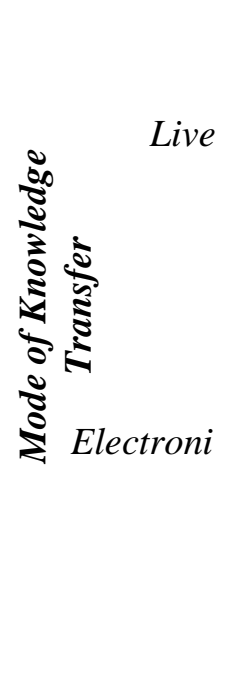 } & $\begin{array}{l}\text { - Mentoring } \\
\text { lapprenticeship } \\
\text { - Phone conversation } \\
\text { or meeting with } \\
\text { expert }\end{array}$ & $\begin{array}{l}\text { - Internal } \\
\text { conferences } \\
\text { - Training programs } \\
\text { - Webcasts }\end{array}$ \\
\hline & $\begin{array}{l}\text { - Shared file systems } \\
\text { and document } \\
\text { stores } \\
\text { - Search engines } \\
\text { - E-mail filters and } \\
\text { personalization } \\
\quad,\end{array}$ & $\begin{array}{l}\text { - Recommended or } \\
\text { required } \\
\text { methodologies and } \\
\text { frameworks } \\
\text { - Expert systems } \\
\text { - Specialized intranet } \\
\text {-. }\end{array}$ \\
\hline & Informal/unstructured & Formal/structured \\
\hline
\end{tabular}

Mengapa Buckman menggunakan TI berbasis knowledge? Apa sesungguhnya dampak TI berbasis knowledge pada organisasi? TI dan manajemen knowledge merupakan dua hal yang tidak dapat dipisahkan. TI akan memotori manajemen knowledge dan knowledge akan mengoptimalkan TI. Dalam organisasi hubungan proses manajemen knowledge berbasis TI terhadap inovasi dan kefektivan organisasi dapat ditunjukan matrik Sabherwal dan Sabherwal (2005) yang disajikan pada gambar 4.

Gambar4:

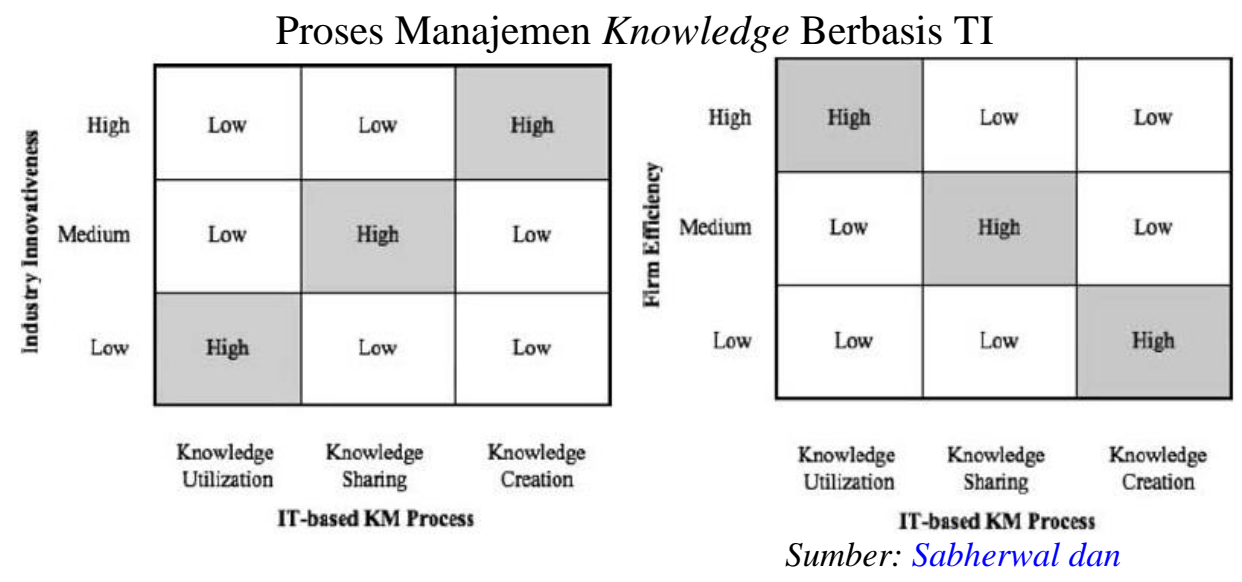


Akhirnya, apa peran inti dalam aplikasi TI berbasis knowledge dalam organisasi? Teknologi yang diaplikasikan dalam organisasi tidak dapat berfungsi dengan optimal tanpa dukungan jaringan pendukung. Faktor manusia masih merupakan komponen utama dalam mengaplikasikan teknologi. Dalam organisasi dapat dibentuk Community of Practices (CoP) baik formal maupun informal sebagai pendukung teknologi. Dalam konsep ini teknologi dapat digunakan sebagai fasilisator dengan membentuk komunitas virtual. Untuk mencapai keberhasilan manajemen knowledge perlu melibatkan grup dan user. Contoh aplikasi CoP dalam organisasi dapat berupa aplikasi komunikasi antar karyawan dalam portal khusus, aplikasi messenger atau portal aspirasi secara anonym.

CoP dapat dikatakan sebagai inti dari keberhasilan aplikasi TI berbasis knowledge dalam organisasi. Contoh keberhasilan perpaduan $\mathrm{CoP}$ dan $\mathrm{TI}$ adalah aplikasi TI pada bank pemerintah di Thailand yang disajikan oleh Wettayaprasit et al (tanpa tahun). Mereka mengilustrasikan CoP tiap cabang dipadukan dengan forum knowledge sharing bank mampu menghubungkan 588 cabang yang tersebar diseluruh Thailand dengan 9010 pengguna.

\section{Simpulan}

Artikel dimulai dengan memabahas peran TI dalam penkomunikasian knowledge yang kemudian diteruskan dengan peran TI dalam mentranfromasikan knowledge, peran TI dalam penyebaran knowledge melalui jaringan, perkembagan teknologi knowledge manajemen, dan diakhiri oleh aplikasi TI berbasis kwoledge. Dari setiap pembahasan dapat diketahui bagaimana TI mamapu membantu dalam mengelolaan asset yang berupa knowledge dengan efektif dan efisien.

Simpulan lain yang dapat ditarik dari pembahasan di dalam artikel adalah: pertama, TI dapat membuka kanal informasi dan dikusi dalam menjaring, menyimpan, dan mengelola knowledge. Kedua, dengan TI tranfromasi knowledge menjadi lebih mudah terjadi dan dapat mempengaruhi setrategi organisasi. Ketiga, TI dapat mendukung penyebaran dan pengelolaan knowledge secara jaringan. Keempat, perkembangan TI dapat mempengaruhi tahap perkembangan dan peran knowledge dalam organisasi. Kelima, aplikasi TI berbasis knowledge dapat meningkatkan sinergi organisasi.

\section{Daftar Pustaka}

Abdullah R. et al, “Applying Knowledge Management System with Agent Technology to Support Decision Making in Collaborative Learning Environment" The Journal of American Academy of Business, Cambridge Vol. 7 Num. 1 *September 2005 pp. 181 - 188 
Allen J. P. "The Evolution of New Mobile Applications: A Sociotechnical Perspective" International Journal of Electronic Commerce Vol. 8, No. 1, Fall 2003, pp. 23-36.

Duffy J., "The Tools and Technologies Needed for Knowledge Management" The information Managemant Journal January 2001, pp. 64 - 67.

Gottschalk P. dan Khandelwal V. K "Stages Of Growth For Knowledge Management Technology In Law Firms" Journal of Computer Information Systems Summer 2004pp. 111 - 124

Kirkland J. How PortBlue fits within the Knowledge Management Universe (2002) http://www.portblue.com

Marwick M. D. "Knowledge Management Technology" IBM System Journal Vol. 40, No 4, 2001, pp. $814-830$

Meek, T, "The Evolution Of Information Technology At Buckman" Knowledge Management Review, Issue 11 November/December 1999

McDermott R. "Why Information Technology Inspired But Cannot Deliver Knowledge Management” California Management Review Vol41. No. 4 , Summer 1999 pp.103-117

Riley T. B. "Knowledge Management And Technology" International Tracking Survey Report '03 Number Two June 3, 2003 http://www.rileyis.com/publications/research_papers/tracking03/IntlTrac kingRptJune03no2.pdf

Sabherwal R. dan Sabherwal S. "Knowledge Management Using Information Technology: Determinants of Short-Term Impact on Firm Value" Decision Sciences Volume 36 Number 4 December 2005 pp. 531 - 567

Sambamurthy, V.dan M. Subramani, "Special Issue On Information Technologies And Knowledge Management" MIS Quarterly Vol. 29 No. 1, March 2005 pp. 1-7

Shand D. "Harnessing Knowledge Management Technologies in R\&D" Knowledge Management Review Issue 3 July - August '98 pp. 20-21

Wagner C. "Wiki: A Technology For Conversational Knowledge Management And Group Collaboration" Communications of the Association for Information Systems, Volume13, 2004 pp. 265-289

Wettayaprasit W. et al "Knowledge Management for Information Technology Section of Government Saving Bank (GSB) in Southern Thailand" 
Zeleny, M. "Knowledge ff Enterprise: Knowledge Management or Knowledge Technology?" International Journal of Information Technology \& Decision Making Vol. 1, No. 2 (2002) pp. 181-207 